\title{
Effects of Hops (Humulus lupulus L.) Beta-Acids on Short Chain Fatty Acid Production from Complex Carbohydrates by Rumen Microbiota
}

\author{
Michael D. Flythe ${ }^{1,2 *}$, Brittany E. Harlow ${ }^{1}$ \\ ${ }^{1}$ Forage-Animal Production Research Unit, Agricultural Research Service, USDA, Lexington, KY, USA \\ ${ }^{2}$ Department of Animal and Food Sciences, College of Agriculture, Food and the Environment, University of Kentucky, Lexington, \\ KY, USA \\ Email: *michael.flythe@usda.gov
}

How to cite this paper: Flythe, M.D. and Harlow, B.E. (2019) Effects of Hops (Humulus lupulus L.) Beta-Acids on Short Chain Fatty Acid Production from Complex Carbohydrates by Rumen Microbiota. Advances in Microbiology, 9, 983-992. https://doi.org/10.4236/aim.2019.912063

Received: September 30, 2019

Accepted: December 8, 2019

Published: December 11, 2019

Copyright $\odot 2019$ by author(s) and Scientific Research Publishing Inc. This work is licensed under the Creative Commons Attribution International License (CC BY 4.0).

http://creativecommons.org/licenses/by/4.0/

\begin{abstract}
The aim of this experiment was to determine the effects of beta-acids, prenylated phenolic compounds from the hops plant, on fermentation of individual carbohydrates by rumen microorganisms. Mixed, uncultivated rumen microbiota was harvested from rumen fistulated steers and washed to make cell suspensions. The suspensions were used to inoculate media with a glucan, fructan or constituent sugar, and fermentation was evaluated by production of short-chain fatty acids (SCFA). Hops beta-acid (30 ppm) was not universally inhibitory, but each of the SCFA (acetate, propionate or butyrate) was decreased $(\mathrm{P}<0.05)$ in one or more of each cellulose or starch tested. The fermentation of sugars and fructans (short- or long-chain inulins) was not impacted by the phytochemicals. Previous results have shown that hops and hops extracts had the beneficial effects of reducing rumen ammonia and methane. The current results indicate that both starch and cellulose fermentation could be impacted. Because cellulose fermentation is nutritionally important on forage-based diets, hops phytochemicals might have more utility in cereal grain-based rations.
\end{abstract}

\section{Keywords}

Rumen Microbiota, Fiber, Phytochemical, Feed Antibiotic

\section{Introduction}

The hops plant (Humulus lupulus L.) is well-known for the production of antimicrobial plant secondary metabolites [1]. The prenylated phloroglucinol compounds, known to brewers as alpha- and beta-acids, inhibit Gram-positive bac- 
teria through disruption of the cell membrane. These phytochemicals intercalate into the membrane and form pores through which ions and other small molecules can pass. When the protonmotive force and intracellular potassium are lost, the bacterial cell is de-energized and cell growth ceases.

The ionophore class of antibiotics has a mechanism of action that is similar to the hop alpha- and beta-acids [2]. Ionophores see little use in human medicine due to their toxicity, but some (e.g. monensin, lasalocid) have been used in ruminant diets for many years [3]. Ionophores inhibit the Gram-positive hyper ammonia-producing bacteria, which increases bypass protein (i.e., survival of protein through the rumen) and promotes weight gain and feed efficiency. Ionophores also inhibit the Gram-positive lactic acid bacteria that ferment starch and are commonly implicated in the development of rumen acidosis. Ruminants are quite insensitive to the ionophore toxicity observed in other animals. It has been conjectured that the observed tolerance of ruminants can be attributed to the binding of ionophores to feed particles and microorganisms in the rumen, which impedes absorption by the ruminant [4]. However, monensin and lasalocid are quite toxic to horses and other animals [5].

It has been proposed that hops phytochemicals could be used as a plant-based alternative to feed antibiotics such as ionophores [6]. Hops beta-acids inhibit hyper ammonia producing bacteria in a manner similar to monensin [7] [8]. They also inhibit methanogenesis and the lactic acid bacteria involved in rumen acidosis [9] [10]. These latter bacteria catabolize starch. Starch fermentation is like protein fermentation, in that, the starch that escapes the rumen is still nutritionally available to the animal [11]. However, other carbohydrates, such as cellulose and hemicelluloses, cannot be digested by mammalian enzymes. The ruminant host relies entirely on the rumen microbiota for metabolic access to these fibers [12]. Thus, if the hops phytochemical spectrum of activity broadly included carbohydrate-utilizing bacteria, then the application would be limited to ruminants on starch-based diets. Indeed, the performance of cattle on high-fiber diets is often not improved by ionophores [13].

The purpose of the current experiment was to determine the effects of hops beta-acid on the fermentation of individual carbohydrates by uncultivated, mixed rumen microbiota in vivo.

\section{Materials and Methods}

\subsection{Media Compositions}

Ball milled cellulose (BMC) was prepared from Whatman \#1 filter paper (Whatman, Tonglu, China; FP) by milling for $14 \mathrm{~d}$ with ceramic grinding media in ball mill (United Nuclear, Laingsburg, MA, USA). Two media types were used based on previous media types [14]. Medium 1: Avicel ${ }^{\circledR}$ micro crystalline cellulose (DuPont, Wilmington, DE, USA; MCC), FP and BMC were fermented in a basal medium that contained (per L): $240 \mathrm{mg} \mathrm{K \textrm {K } _ { 2 }} \mathrm{PO}_{4}, 240 \mathrm{mg} \mathrm{K} \mathrm{HPO}_{4}, 480 \mathrm{mg}$ $\left(\mathrm{NH}_{4}\right)_{2} \mathrm{SO}_{4}, 480 \mathrm{mg} \mathrm{NaCl}, 64 \mathrm{mg} \mathrm{CaCl} \cdot \mathrm{H}_{2} \mathrm{O}, 100 \mathrm{mg} \mathrm{MgSO} \cdot 7 \mathrm{H}_{2} \mathrm{O}, 600 \mathrm{mg}$ 
cysteine hydrochloride, $1.0 \mathrm{mg}$ phenylacetate, $1000 \mathrm{mg}$ Trypticase, $500 \mathrm{mg}$ Yeast Extract and $3.1 \mathrm{~mL}$ of a short-chain fatty acid solution described by Cotta and Russell [14] to meet the nutritional requirements of cellulolytic bacteria. The $\mathrm{pH}$ was adjusted to 6.5 by dropwise addition of a $20 \% \mathrm{NaOH}$ aqueous solution. The medium was thermally degassed in an autoclave (Tomy, Tokyo, Japan; $121^{\circ} \mathrm{C}, 15$ psi, $15 \mathrm{~min}$ ) and cooled to room temperature under $\mathrm{O}_{2}$-free $\mathrm{CO}_{2}$. Buffer $(4.0 \mathrm{~g}$ $\mathrm{Na}_{2} \mathrm{CO}_{3}$ ) was added, which brought the final $\mathrm{pH}$ to 6.7. The medium was anaerobically dispensed into Balch tubes (Chemglass, Vineland, NJ, USA) containing the substrates. The tubes were stoppered with butyl rubber stoppers, sealed with aluminum crimp seals and autoclaved for sterility (Tomy, Tokyo, Japan; $121^{\circ} \mathrm{C}$, $15 \mathrm{psi}, 15 \mathrm{~min})$.

The starch, inulin and sugar substrates were fermented in medium 2, which was prepared in the same way as medium 1, except it did not contain the SCFA solution. The soluble potato starch was manufactured by Alfa Aesir (Ward Hill, MA, USA). The corn and wheat starch were manufactured by Grain Millers, Incorporated (Marion, IN, USA). The inulins were manufactured by Beneo-Orafti (Morris Plains, NJ, USA). The long-chain inulin was Orafti ${ }^{\circledR} \mathrm{HP}, \mathrm{DP} \geq 23$. The short-chain inulin was Orafti $^{\circledR}$ OPS, DP $\leq 10$.

\subsection{Animals and Diets}

All animal procedures were approved by the University of Kentucky Animal Care and Use Committee (Lexington, KY, USA). All animal procedures and husbandry were performed according to the Guide for the Care and Use of Agricultural Animals in Research and Teaching [15]. Three rumen-fistulated, mature, Holstein steers were used as rumen digesta donors. Steers were fed corn silage with water and mineral ad libitum.

\subsection{Washed Cell Suspensions and Fermentation}

Rumen contents $(\sim 0.25 \mathrm{~kg} / \mathrm{sample})$ were collected separately from three steers. Dorsal and ventral parts of the rumen were sampled by hand through the rumen fistula with an obstetric sleeve. Immediately post-collection, rumen content samples were transported to the laboratory in a sealed, insulated container within $1 \mathrm{hr}$ of collection. Upon arrival, the digesta were squeezed through 4 layers of cheesecloth into a centrifuge bottle (approx. $250 \mathrm{~mL}$ in a $500 \mathrm{~mL}$ bottle) and subjected to low speed centrifugation $(100 \times \mathrm{g}, 10 \mathrm{~min})$ in a floor centrifuge (Sorvall RC6 Plus, Thermo Scientific, Waltham, MA, USA) to remove large feed particles. The supernatant was collected and subjected to centrifugation to harvest prokaryote-sized organisms $(25600 \times \mathrm{g}, 10 \mathrm{~min})$. The pellets were resuspended in medium 2, washed and harvested a second time $(25600 \times \mathrm{g}, 10 \mathrm{~min})$. The pellets were suspended in the appropriate medium to a cell density of 10.0 OD (Biowave II spectrophotometer, Biochrom, Cambridge, UK). The cell suspensions were sparged with $\mathrm{CO}_{2}$ in serum bottles and $1 \mathrm{~mL}$ cell suspension was anaerobically transferred to tubes that contained $9 \mathrm{~mL}$ of the appropriate me- 
dium and $40 \mathrm{mg}$ substrate. Hops extract (Beta-Bio, S. S. Steiner, Yakama, WA; $45 \% \mathrm{w} / \mathrm{w}$ co-lupulone and ad-lupulone in a base of propylene glycol) was added to achieve $30 \mathrm{ppm}$ total beta-acids when indicated. The tubes were incubated $\left(39^{\circ} \mathrm{C}, 120 \mathrm{rpm}\right)$ for $48 \mathrm{~h}$. Samples were collected non-destructively at 0,24 and $48 \mathrm{~h}$ with a tuberculin syringe and needle. The samples were clarified by centrifugation $(21,000 \times \mathrm{g}, 2 \mathrm{~min})$ and frozen $\left(-20^{\circ} \mathrm{C}\right)$ for later analysis.

\subsection{Chemical Analysis}

The samples were thawed and clarified of remaining particles by centrifugation $(21,000 \times \mathrm{g}, 2 \mathrm{~min})$. Short-chain fatty acids were quantified by HPLC with a UV detector (Dionex; Sunnyvale, CA, USA) and equipped with an anion exchange column (Aminex HP-87H; Biorad, Hercules, CA, USA). The eluent was an aqueous solution of sulfuric acid $(5 \mathrm{mM})$. The operational parameters were injection volume $0.1 \mathrm{~mL}$, flow rate $0.4 \mathrm{~mL} \cdot \mathrm{min}^{-1}, 50^{\circ} \mathrm{C}$ column temperature. The injection times were $70 \mathrm{~min}$. Data were analyzed using Chromeleon software (version 7; Thermo; Sunnyvale, CA, USA).

\subsection{Replication and Statistical Analysis}

The fermentations were conducted three times on each substrate. A different rumen digesta donor animal was used each time. Initial, 24 and $48 \mathrm{~h}$ samples were analyzed and the greatest product concentrations for each of the fermentations were averaged and compared between the control and hop extract-treatment. The mean concentrations of an individual or total short-chain fatty acids were compared using paired Student's T-tests. Concentrations were considered different when the P-value was less than 0.05 .

\section{Results}

Fermentations by uncultivated, washed rumen microorganisms from steers were evaluated by short-chain fatty acid (SCFA) production. The acids analyzed included acetic, propionic and butyric acid. In some cases, fermentations lagged or SCFA peaked and then decreased. The greatest concentrations observed were used in these comparisons. Table 1 shows SCFA in fermentations with glucans or glucose. The glucans included three types of cellulose, $\beta(1 \rightarrow 4)$ glucan. Both acetate and propionate production from microcrystalline cellulose (MCC) decreased in the presence of hop beta-acids. There were no effects on SCFA from intact filter paper strips. However, more SCFA was produced from the filter paper when it was ground in a ball mill to increase surface area. The addition of beta-acids decreased acetate, propionate and total SCFA. The fermentation of oat $\beta(1 \rightarrow 3)$ glucan and glucose were not altered by hop beta-acids.

Table 2 shows SCFA in fermentations with starches or maltose. The starches included three types of starch, $\alpha(1 \rightarrow 4)$ glucan. Acetate production from soluble potato starch decreased in the presence of hop beta-acids, but propionate, butyrate and total SCFA were not significantly changed. Acetate and butyrate 
Table 1. Effects of hops beta acids on SCFA production from cellulose, oat beta glucans or glucose.

\begin{tabular}{|c|c|c|c|c|c|}
\hline \multirow{2}{*}{ Carbohydrate } & \multirow{2}{*}{$\beta$-acid $(+/-)$} & \multicolumn{3}{|c|}{ Short-Chain Fatty Acid (mM) } & \multirow{2}{*}{ Tota } \\
\hline & & Acetic & Propionic & Butyric & \\
\hline \multirow{2}{*}{ Microcrystalline Cellulose } & - & 35.3 & 28.0 & 7.4 & 70.7 \\
\hline & + & $25.0^{*}$ & $11.5^{*}$ & 6.7 & $43.2^{\star}$ \\
\hline \multirow{2}{*}{ Whatman paper strip } & - & 30.3 & 17.6 & 6.8 & 54.8 \\
\hline & + & 25.0 & 11.2 & 7.1 & 43.3 \\
\hline \multirow{2}{*}{ Ball-milled paper } & - & 37.0 & 23.3 & 7.5 & 67.8 \\
\hline & + & $25.0^{*}$ & $12.0^{*}$ & 7.6 & $44.6^{*}$ \\
\hline \multirow[b]{2}{*}{ Oat beta-glucan } & - & 12.0 & 12.3 & 9.1 & 33.4 \\
\hline & + & 12.3 & 16.0 & 9.5 & 37.8 \\
\hline \multirow{2}{*}{ Glucose } & - & 12.0 & 14.0 & 10.5 & 36.5 \\
\hline & + & 9.4 & 16.9 & 8.3 & 34.6 \\
\hline
\end{tabular}

Fermentations were conducted with mixed, washed rumen microorganisms and $4 \mathrm{mg} \cdot \mathrm{mL}^{-1}$ carbohydrate as indicated. The incubations $\left(39^{\circ} \mathrm{C}\right)$ were sampled at 24 and $48 \mathrm{~h}$ and the highest values for each SCFA were recorded. Hops extract was added to achieve $30 \mathrm{ppm} \beta$-acid when indicated. There were three replicates using rumen microbiota from different animal donors. SCFA from each substrate was compared with and without $\beta$-acid using a paired Student's T-test. An asterisk $\left.{ }^{*}\right)$ indicates the $\beta$-acid treatment was different than the control $(\mathrm{P}<0.05)$.

Table 2. Effects of hops beta acids on SCFA production from starches or maltose.

\begin{tabular}{|c|c|c|c|c|c|}
\hline \multirow{2}{*}{ Carbohydrate } & \multirow{2}{*}{$\beta$-acid (+/-) } & \multicolumn{3}{|c|}{ Short-Chain Fatty Acid (mM) } & \multirow{2}{*}{ Total } \\
\hline & & Acetic & Propionic & Butyric & \\
\hline \multirow{2}{*}{ Soluble potato starch } & - & 15.3 & 16.0 & 5.6 & 36.9 \\
\hline & + & $10.1^{*}$ & 17.3 & 5.5 & 32.9 \\
\hline \multirow[b]{2}{*}{ Corn starch } & - & 16.6 & 10.1 & 10.3 & 37.1 \\
\hline & + & $10.6^{*}$ & 15.4 & $6.7^{\star}$ & 32.7 \\
\hline \multirow{2}{*}{ Wheat starch } & - & 15.6 & 7.7 & 12.0 & 35.2 \\
\hline & + & 12.0 & $19.0^{*}$ & 7.4 & 38.4 \\
\hline \multirow{2}{*}{ Maltose } & - & 12.6 & 14.2 & 10.6 & 37.4 \\
\hline & + & 12.0 & 17.3 & 8.2 & 37.5 \\
\hline
\end{tabular}

Fermentations were conducted with mixed, washed rumen microorganisms and $4 \mathrm{mg} \cdot \mathrm{mL}^{-1}$ carbohydrate as indicated. The incubations $\left(39^{\circ} \mathrm{C}\right)$ were sampled at 24 and $48 \mathrm{~h}$ and the highest values for each SCFA were recorded. Hops extract was added to achieve $30 \mathrm{ppm} \beta$-acid when indicated. There were three replicates using rumen microbiota from different animal donors. SCFA from each substrate was compared with and without $\beta$-acid using a paired Student's T-test. An asterisk $\left.{ }^{*}\right)$ indicates the $\beta$-acid treatment was different than the control $(\mathrm{P}<0.05)$.

production from corn starch were impacted by beta-acid, but propionate was not affected. Propionate production from wheat starch increased in the presence of beta-acids. Like glucose, the fermentation of maltose was not altered by the phytochemical.

Table 3 shows SCFA production from fructans or fructose. Long-chain inulin, 
Table 3. Effects of hops beta acids on SCFA production from inulins or fructose.

\begin{tabular}{cccccc}
\hline \multirow{2}{*}{ Carbohydrate } & \multirow{2}{*}{$\boldsymbol{\beta}$-acid (+/-) } & \multicolumn{2}{c}{ Short-Chain Fatty Acid (mM) } & \multirow{2}{*}{ Total } \\
\cline { 3 - 5 } & & Acetic & Propionic & Butyric & \\
\hline \multirow{2}{*}{ Long-chain inulin } & - & 16.0 & 19.0 & 8.3 & 43.3 \\
& + & 14.3 & 14.5 & 10.5 & 39.4 \\
\multirow{2}{*}{ Short-chain inulin } & - & 12.3 & 13.0 & 13.8 & 39.1 \\
\multirow{2}{*}{ Fructose } & + & 13.4 & 14.3 & 10.8 & 38.5 \\
& - & 12.0 & 13.3 & 11.0 & 36.3 \\
\hline
\end{tabular}

Fermentations were conducted with mixed, washed rumen microorganisms and $4 \mathrm{mg} \cdot \mathrm{mL}^{-1}$ carbohydrate as indicated. The incubations $\left(39^{\circ} \mathrm{C}\right)$ were sampled at 24 and $48 \mathrm{~h}$ and the highest values for each SCFA were recorded. Hops extract was added to achieve $30 \mathrm{ppm} \beta$-acid when indicated. There were three replicates using rumen microbiota from different animal donors. SCFA from each substrate was compared with and without $\beta$-acid using a paired Student's T-test. An asterisk $\left.{ }^{*}\right)$ indicates the $\beta$-acid treatment was different than the control $(\mathrm{P}<0.05)$.

short-chain inulin or fructose were added as substrates. All of these substrates fermented over the $24 \mathrm{~h}$ incubation period, but there were no SCFA differences between hop beta-acid treatments and controls.

\section{Discussion}

In recent years, there has been concern about the use of feed antibiotics to promote growth and feed efficiency in animals [16] [17]. However, feed efficiency is actually an environmental quality issue, and growth promoting antibiotics (i.e. ionophores) decrease the methane and ammonia lost from ruminant operations [18]. The consequences of reducing the use of growth promoting technologies are both economic and environmental [19]. Thus, identification and development of non-antibiotic growth promoters are important to the sustainability of ruminant industries.

Our research group and others proposed that hops beta-acids have some of the characteristics desirable in a phytochemical ruminant growth promoter [6]. Beta-acids have a well-described ionophore-like mechanism of action on model bacteria [1] as well as on the rumen bacteria used to originally elucidate how monensin influences rumen ammonia production [7] [20] [21]. We also previously have shown that beta-acid inhibits the bacteria associated with rumen acute acidosis [10]. These later experiments showed that beta-acids inhibited carbohydrate fermentation and could change the ratios of SCFA production. The Gram-positive lactic acid bacterium, Streptococcus bovis, was inhibited. However, the Gram-negative Negativicutes, Selenomonas ruminantium and Megasphaera elsdenii were not sensitive. Notably, these later experiments employed mixed carbohydrates. It was not clear how beta-acids would affect fermentation of individual carbohydrates.

The results that beta-acids inhibit starch fermentation are consistent with previous findings and the phyto-ionophore mechanism of action. Three starches 
were used to capture a broader picture of amylolytic activity. The soluble starch is typically what is used in the laboratory to make starch-based media. Ruminants are not usually fed isolated starch, but the corn and wheat starch were more like what rumen microorganisms might actually encounter in situ. More propionate was produced from wheat starch in the presence of beta-acids, which is consistent with the previous observation that propionate producing bacteria, like S. ruminantium and $M$. elsdenii were not sensitive [10]. It is possible that these later bacteria were promoted on wheat starch when ecological competitors were inhibited.

The fructans used in the experiment were readily fermented by the cell suspensions of rumen microorganisms. The inability of beta-acids to inhibit fermentation of these oligofructose compounds was surprising. A previous study explored the effects of beta-acids on fructan fermentation by equine fecal bacteria [22]. In that case, beta-acids had a dramatic inhibitory effect on SCFA production and pH. Streptococcus bovis was the predominant fructanolytic species in horses from which the microorganisms were collected. Streptococcus bovis has a Gram-positive cell envelope, and the susceptibility of multiple isolates to beta-acids has been shown [10] [22]. Streptococcus bovis is a numerically dominant rumen species only under particular conditions [11]. The other studied fructanolytic species is Butyrivibrio fibrisolvens [23], but its susceptibility to hops beta-acids has not been determined. It is plausible that the predominant fructanolytic rumen bacteria in the steers could have been Gram-negative or otherwise insensitive to the beta-acids at the concentration used. The differences between bovine and equine fructanolytic microorganisms and how those differences direct responses to fructans warrants further study.

The rumen cellulolytic bacteria include well-studied species such as Fibrobacter succinogenes, Butyrivibrio fibrisolvens, Ruminococcus albus and R. flavifaciens [24]. Notably, the often numerous ruminococci are Gram-positive. Thus, the effects of beta-acids on SCFA production from cellulose are expected results. These results are consistent with the effects of well-studied feed ionophores that are typically used in starch-based rations such as dairy and fattening, or finishing, as it is called in the USA [3] [17]. Ionophores are also useful as coccidiostats, but poor performance is sometimes noted on forage-based diets, in which most of the calories come from fiber [13]. The ruminant host requires the fibrolytic microorganisms to provide metabolic access to cellulose and hemicelluloses. When some of the fibrolytic populations are suppressed it is reasonable to expect differences in fiber fermentation.

In vivo experiments such as this one are short-term, and do not permit adaptation to diets and inhibitors in the same manner as feeding trials. However, these results suggest that hops or hops phytochemicals could be more useful in some diets than others. There is interest in brewery ruminant co-products with high levels of hop phytochemicals. Some results have shown that spent brewers' yeast inhibited rumen ammonia and methane production [25] [26]. Another 
study indicates that older stored hops are adequately antimicrobial for feeding applications even after they are no longer desirable by brewers [27]. The antimicrobial spectrum of activity of hop phytochemicals should be considered when planning diets to test these co-products.

\section{Disclaimer}

Mention of trade names or commercial products in this publication is solely for the purpose of providing specific information and does not imply recommendation or endorsement by the U.S. Department of Agriculture. USDA is an equal opportunity provider and employer.

\section{Acknowledgements}

The research was funded by the United States Department of Agriculture, Agricultural Research Service as part of National Program 101, Food Animal Production. We thank donors for several of the materials used in the experiment. S.S. Steiner donated the "Beta-Bio" hops extract. Beneo Orafti donated the inulins. Grain Millers, Inc. donated the corn and wheat starch. We thank Gloria Gellin and Tracy Hamilton for technical support.

\section{Conflicts of Interest}

The authors declare no conflicts of interest regarding the publication of this paper.

\section{References}

[1] Teuber, M. and Schmalreck, A.F. (1973) Membrane Leakage in Bacillus subtilis 169 Induced By the Hop Constituents Lupulone, Humulone, Isohumulone and Humulinic Acid. Archives of Microbiology, 94, 159-171. https://doi.org/10.1007/BF00416690

[2] Haney, M.E. and Hoehn, M.M. (1967) Monensin, a New Biologically Active Compound. I. Discovery and Isolation. Antimicrobial Agents and Chemotherapy, 7, 349-351.

[3] Russell, J.B. and Strobel, H.J. (1989) Effect of Ionophores on Ruminal Fermentation. Applied and Environmental Microbiology, 55, 1-6.

[4] Chow, J.M., Van Kessel, J.A. and Russell, J.B. (1994) Binding of Radiolabeled Monensin and Lasalocid to Ruminal Microorganisms and Feed. Journal of Animal Science, 72, 1630-1635. https://doi.org/10.2527/1994.7261630x

[5] Oehme, F.W. and Pickrell, J.A. (1999) An Analysis of the Chronic Oral Toxicity of Polyether Ionophore Antibiotics in Animals. Veterinary and Human Toxicology, 41, 251-257.

[6] Flythe, M.D., Kagan, I.A., Wang, Y. and Narvaez, N. (2017) Hops (Humulus lupulus L.) Bitter Acids: Modulation of Rumen Fermentation and Potential as an Alternative Growth Promoter. Frontiers in Veterinary Science, 4, 131. https://doi.org/10.3389/fvets.2017.00131

[7] Flythe, M.D. (2009) The Antimicrobial Effects of Hops (Humulus Lupulus L.) on Ruminal Hyper Ammonia-Producing Bacteria. Letters in Applied Microbiology, 
118, 242-248. https://doi.org/10.1111/j.1472-765X.2009.02600.x

[8] Flythe, M.D., Aiken, G.E., Gellin, G.L., Klotz, J.L., Goff, B.M. and Andries, K.M. (2015) Hops (Humulus lupulus) Beta-Acid as an Inhibitor of Caprine Rumen Hyper-Ammonia-Producing Bacteria in Vitro. Agriculture, Food and Analytical Bacteriology, 5, 29-36.

[9] Narvaez, N., Wang, Y., Xu, Z. and McAllister, T. (2011) Effects of Hops on in Vitro Ruminal Fermentation of Diets Varying in Forage Content. Livestock Science, 138, 193-201. https://doi.org/10.1016/j.livsci.2010.12.028

[10] Flythe, M.D. and Aiken, G.E. (2010) Effects of Hops (Humulus Lupulus L.) Extract on Volatile Fatty Acid Production by Rumen Bacteria. Journal of Applied Microbiology, 109, 1169-1176. https://doi.org/10.1111/j.1365-2672.2010.04739.x

[11] Nagaraja, T.G. and Titgemeyer, E.C. (2007) Ruminal Acidosis in Beef Cattle: The Current Microbiological and Nutritional Outlook. Journal of Dairy Science, 90, E17-E38. https://doi.org/10.3168/jds.2006-478

[12] Hungate, R.E. (1944) Studies on Cellulose Fermentation: I. The Culture and Physiology of an Anaerobic Cellulose-Digesting Bacterium. Journal of Bacteriology, 48, 499-513.

[13] Aiken, G.E. and Brown, M.A. (1996) Steer Responses to Protein Supplementation and Lasalocid on Bermudagrass Pasture. The Professional Animal Scientist, 12, 109-113. https://doi.org/10.15232/S1080-7446(15)32499-2

[14] Cotta, M.A. and Russell, J.B. (1982) Effects of Peptides and Amino Acids on Efficiency of Rumen Bacterial Protein Synthesis in Continuous Culture. Journal of Dairy Science, 65, 226-234. https://doi.org/10.3168/jds.S0022-0302(82)82181-4

[15] F.A.S.S. (2010) Guide for the Care and Use of Agricultural Animals in Research and Teaching. 3rd Edition, Federation of Animal Science Societies, Champaign, IL.

[16] McEachran, A.D., Blackwell, B.R., Hanson, J.D., Wooten, K.J., Mayer, G.D., Cox, S.B. and Smith, P.N. (2015) Antibiotics, Bacteria, and Antibiotic Resistance Genes: Aerial Transport from Cattle Feed Yards via Particulate Matter. Environmental Health Perspectives, 123, 337-343. https://doi.org/10.1289/ehp.1408555

[17] Callaway, T.R., Edrington, T.S., Rychlik, J.L., Genovese, K.J., Poole, T.L., Jung, Y.S., Bischoff, K.M., Anderson, R.C. and Nisbet, D.J. (2003) Ionophores: Their Use as Ruminant Growth Promotants and Impact on Food Safety. Current Issues in Intestinal Microbiology, 4, 43-51.

[18] Tedeschi, L.O., Fox, D.G. and Tylutki, T.P. (2003) Potential Environmental Benefits of Ionophores in Ruminant Diets. Journal of Environmental Quality, 32, 1591-1602. https://doi.org/10.2134/jeq2003.1591

[19] Capper, J.L. and Hayes, D.J. (2012) The Environmental and Economic Impact of Removing Growth-Enhancing Technologies from U.S. Beef Production. Journal of Animal Science, 90, 3527-3537. https://doi.org/10.2527/jas.2011-4870

[20] Russell, J.B., Strobel, H.J. and Chen, G.J. (1988) Enrichment and Isolation of a Ruminal Bacterium with a Very High Specific Activity of Ammonia Production. Applied and Environmental Microbiology, 54, 872-877.

[21] Chen, G.J. and Russell, J.B. (1989) More Monensin-Sensitive, Ammonia-Producing Bacteria from the Rumen. Applied and Environmental Microbiology, 55, 1052-1057.

[22] Harlow, B.E., Lawrence, L.M., Kagan, I.A. and Flythe, M.D. (2014) Inhibition of Fructan-Fermenting Equine Faecal Bacteria and Streptococcus bovis by Hops (Humulus Lupulus L.) B-Acid. Journal of Applied Microbiology, 117, 329-339. https://doi.org/10.1111/jam.12532 
[23] Kasperowicz, A., Stan-Głasek, K. and Michałowski, T. (2015) The Fructanolytic Abilities of the Rumen Bacterium Butyrivibrio fibrisolvens Strain 3071. Journal of Applied Microbiology, 120, 29-40. https://doi.org/10.1111/jam.12976

[24] Russell, J. and Rychlik, J. (2001) Factors That Alter Rumen Microbial Ecology. Science, 11, 1119-1122. https://doi.org/10.1126/science.1058830

[25] Harlow, B.E., Bryant, R.W., Cohen, S.D., O'Connell, S.P. and Flythe, M.D. (2016) Degradation of Spent Craft Brewer's Yeast by Caprine Rumen Hyper Ammonia-Producing Bacteria. Letters in Applied Microbiology, 63, 307-312. https://doi.org/10.1111/lam.12623

[26] Pszczolkowski, V.L., Bryant, R.W., Harlow, B.E., Aiken, G.E., Martin, L.J. and Flythe, M.D. (2016) Effects of Spent Craft Brewers' Yeast on Fermentation and Methane Production by Rumen Microorganisms. Advances in Microbiology, 6, 716-723. https://doi.org/10.4236/aim.2016.69070

[27] Flythe, M.D., Harlow, B.E., Aiken, G.E., Gellin, G.L., Kagan, I.A., and Pappas, J. (2017) Inhibition of Growth and Ammonia Production of Ruminal Hyper Ammonia-Producing Bacteria by Chinook or Galena Hops after Long-Term Storage. Fermentation, 3, 1-9. https://doi.org/10.3390/fermentation3040068 